University of Nebraska - Lincoln

DigitalCommons@University of Nebraska - Lincoln

U.S. Environmental Protection Agency Papers

U.S. Environmental Protection Agency

2004

Developmental Disruption of Thyroid Hormone: Correlations with Hearing Dysfunction in Rats

K. M. Crofton

U.S. Environmental Protection Agency, crofton.kevin@epa.gov

Follow this and additional works at: https://digitalcommons.unl.edu/usepapapers

Crofton, K. M., "Developmental Disruption of Thyroid Hormone: Correlations with Hearing Dysfunction in Rats" (2004). U.S. Environmental Protection Agency Papers. 124.

https://digitalcommons.unl.edu/usepapapers/124

This Article is brought to you for free and open access by the U.S. Environmental Protection Agency at DigitalCommons@University of Nebraska - Lincoln. It has been accepted for inclusion in U.S. Environmental Protection Agency Papers by an authorized administrator of DigitalCommons@University of Nebraska - Lincoln. 


\title{
Developmental Disruption of Thyroid Hormone: Correlations with Hearing Dysfunction in Rats
}

\author{
K. M. Crofton*
}

\begin{abstract}
A wide variety of environmental contaminants adversely affect thyroid hormone (TH) homeostasis. Hypothyroidism and/or hypothyroxinemia during the early postnatal period in the rat leads to permanent structural damage and loss of function in the cochlea. A major uncertainty in assessing the risks of developmental exposure to thyroid-disrupting chemicals (TDCs) is the lack of a clear characterization of the dose-response relationship, especially in the lower region, between disruption of hormones and adverse consequences. The current work correlated early postnatal hypothyroxinemia with hearing loss in the adult rat. Linear regression was performed on the log transform for total serum thyroxine (T4) concentrations on postnatal day 14 or 21 versus $\mathrm{dB}(\mathrm{SPL})$ of hearing loss in adult animals developmentally exposed to TDCs. Regression analyses revealed a highly significant correlation between T4 concentration and hearing loss. In the rat, a 50-60\% decrease in circulating T4 was needed to significantly impact hearing function. This correlation suggests that T4 serum concentrations at 14 or 21 days of postnatal age may be a good predictive biomarker in rodents of the adverse consequence of developmental exposure to TDCs.
\end{abstract}

KEY WORDS: Developmental thyroid disruption; endocrine disruptors; hearing loss

\section{INTRODUCTION}

Broadly defined, thyroid-disrupting chemicals (TDCs) are chemicals that alter the structure or function of the thyroid gland, alter regulatory enzymes associated with thyroid hormones (THs), or change circulating or tissue concentrations of THs. A wide range of chemicals with diverse structures act as TDCs (Colborn et al., 1993; Brouwer et al., 1998; BruckerDavis, 1998; Hurley, 1998; DeVito et al., 1999; Zoeller \& Crofton, 2000; Porterfield, 2000). Some chemicals, such as perchlorate, inhibit the uptake of iodide into the thyroid and subsequently decrease $\mathrm{TH}$ synthesis (Wolff, 1998). Other chemicals decrease TH synthesis by inhibition of thyroid peroxidase (McClain, 1995;

\footnotetext{
* Neurotoxicology Division, National Health and Environmental Effects Research Laboratory, Office of Research and Development, U.S. EPA, Research Triangle Park, NC 27711, USA; crofton.kevin@epa.gov.
}

Capen, 1997, 1998; Hill et al., 1998; Hurley, 1998). A number of chemicals alter the catabolism of THs via upregulation of TH-glucuronidation, which increases biliary elimination of these hormones (Oppenheimer et al., 1968; McClain et al., 1989; Hood \& Klaassen, 2000; Klaassen \& Hood, 2001). A hallmark effect of these diverse chemicals is the decrease in serum TH concentrations (Hill et al., 1998; Hurley, 1998; Brucker-Davis, 1998; DeVito et al., 1999).

Thyroid hormone insufficiency can have two major consequences depending on the age of the organism when the exposure occurs. Effects of hypothyroidism acquired in adult humans can lead to any of a number of nonspecific clinical signs such as fatigue and constipation, dry skin, muscle cramps, and menorrhagis (Ladenson, 2000). In adult rodent models an additional effect of long-term thyroid disruption is thyroid tumor formation consequent to overstimulation of the thyroid gland via upregulation of thyroid 
stimulating hormone (TSH) (McClain, 1995; Capen, 1994, 1997, 1998; Hill et al., 1998). Effects due to TSH upregulation, with the exception of the tumors in rodent models, are transient effects resulting from transient disruption, i.e., removal of the disrupting agent, or hormone supplementation will ameliorate the effects (McClain, 1995; Capen, 1998; Hill et al., 1998). In contrast, work with laboratory animal models as well as human studies clearly documents that transient disruption of thyroid function during development results in permanent effects, especially on the developing nervous system (cf. Boyages \& Halpern, 1993; Porterfield, 2000; Delange, 2000; Morreale de Escobar, 2001; Zoeller et al., 2002; Howdeshell, 2002). These effects in the developing organism are independent of TSH and result from decreases in tissue levels of T4 and T3.

A major uncertainty that hampers the risk assessment of TDCs is the lack of a clear characterization of the dose-response relationship between the degree of change in hormone concentrations and adverse consequences. While serum concentrations of THs are useful biomarkers of the effects of thyroid toxicants on thyroid homeostasis, the relationship between the degree of alteration of $\mathrm{TH}$ and developmental toxicity is less certain. The animal model literature is replete with examples of the effects of hypothyroidism on the development and maturation of the nervous system; however, almost the entirety of the experimental work consists of animal models in which THs are severely depleted by high doses of thryotoxicants (e.g., Uziel et al., 1981; Hendrich \& Porterfield, 1996; Timiras \& Nzekwe, 1989; Morrealle de Escobar et al., 1993; Lavado-Autric et al., 2003). Mechanistic proof of thyroid dependency is usually offered by demonstrating that $\mathrm{TH}$ replacement ameliorates the effect of the TDC (e.g., Uziel et al., 1981; Escobar-Morreale et al., 1997; Goldey \& Crofton, 1998; Sprenkle et al., 2001). While this increases knowledge about the role of THs in nervous system development, it does not prove as useful in estimating risks from environmental TDCs.

In humans, exposures to environmental contaminants that adversely impact thyroid homeostasis will likely result in only mild perturbations of THs (e.g., Koopman-Esseboom et al., 1994; Nagayama et al., 1998; Fiolet et al., 1997; Langer et al., 1998; Longnecker et al., 2000). Use of data from animal models to inform how these mild perturbations in humans link to adverse consequences in the developing brain is hampered by lack of dose-response information. This lack of relevant low-dose data from animal studies (i.e, small effects on THs) is in contrast to recent data from human studies suggesting that small decrements $(\sim 25 \%)$ in maternal thyroxine during pregnancy result in significant decreases in indices of mental development (Man, 1972; Man et al., 1991; Haddow et al., 1999; Pop et al., 1999; Morreale de Escobar et al., 2000).

Previous reports in rats have documented the relationship between THs in late prenatal/early postnatal periods, a time that corresponds to ongoing cochlear development (Rubel, 1978, 1984; Müller, 1991), and alterations in the structure and function of the auditory system in rats (Puel \& Uziel, 1987; Uziel, 1986). Other reports have related the hypothyroxinemia induced by polyhalogenated aromatic hydrocarbon (PHAH) exposures to low-frequency hearing loss in rats (Goldey et al., 1995a; Herr et al., 1996; Goldey \& Crofton, 1998; Crofton et al., 2000a). This hearing loss persists into adulthood despite recovery to a euthyroid state following cessation of exposure (Goldey \& Crofton, 1998). The purpose of the present work was to characterize the relationship between the degree of postnatal hypothyroxinemia and hearing loss in a rodent model. More specifically, through the use of regression analysis, the purpose was to determine the degree of hypothyroxinemia needed to produce the minimally significant alternation in auditory function. The present work analyzed postnatal thyroxine (T4) and hearing loss data from previous research in this laboratory.

\section{METHODS}

\subsection{Data Sources}

Data were abstracted from previous reports (Table I). Serum total T4 concentrations from either postnatal day (PND) 14 or 21 were used in this analysis. PND 14 data were used if available; otherwise data from PND 21 were used. The effect of PHAHs on postnatal total serum $\mathrm{T} 4$ is approximately equal and maximal at these two ages (Goldey et al., 1995a; Crofton et al., 2000b). Litter sizes in these experiments ranged from 6-12 litters per treatment group. Both male and female offspring were tested. Due to limited serum volume, and previous data suggesting a lack of sex-dependent effects, T4 data were pooled by litter for PND14 and 21. This comparison also includes data from one non-PHAH, propylthiouracil (Goldey et al., 1995b). These data were included because they were collected in the same laboratory using the same auditory testing procedures. 
Table I. List of Data Sources

\begin{tabular}{|c|c|}
\hline Chemical & References \\
\hline Aroclor 1254 & $\begin{array}{l}\text { Goldey et al. (1995b); Goldey and Crofton } \\
\text { (1998); Crofton et al. (1998); Crofton et al. } \\
\text { (2000b) }\end{array}$ \\
\hline Propylthiouracil & Goldey et al. (1995a) \\
\hline Dioxin & Goldey et al. (1996) \\
\hline РCB 126 & Crofton and Rice (1999) \\
\hline \multirow[t]{2}{*}{ DE-71 } & Taylor et al. (2003) \\
\hline & Zhou et al. (2002) \\
\hline
\end{tabular}

\subsection{Endpoints}

All data were collected using the same methods (see individual papers cited in Table I for detailed descriptions of the methods). Briefly, total serum concentrations of thyroxine (T4) were measured using radioimmunoassay kits (Diagnostic Products Corp., Los Angeles, CA) as previously described (Goldey et al., 1995a; Goldey \& Crofton, 1998). Auditory thresholds were measured in adult offspring at approximately the same age (PND90-120) using the reflex modification audiometry (RMA) procedure of Young and Fechter (1983) as modified by Crofton et al. (1990). Thresholds for $1 \mathrm{kHz}$ were abstracted from all reports since this frequency was shown to be most sensitive to PHAHs (Goldey et al., 1995a; Herr et al., 1996).

\subsection{Data Analyses}

Thresholds were not determined in the same animals in which T4 concentrations were determined, and individual data from some older studies were not available. Therefore, group mean data were used in the analyses. In all cases, however, the data for both measures were from the same experiments. T4 data were transformed to percent control to correct for differences between studies. Thresholds were expressed as the difference score between the treated and control group in dB SPL. A simple linear regression analysis was run using SigmaPlot (version 8, SPSS, Chicago, IL). The data were fit to the following equation: $y=(m \times \log x)+b$. T4 values were $\log$ transformed to linearize the data. (Only data from treated groups were used in the correlation, i.e., no control data were used.) The data set contained one data point from the PTU study (Goldey et al., 1995a) with extremely low T4 concentrations and a high degree of hearing loss (see Fig. 1). To control for the potential bias of this one data point on the correla-

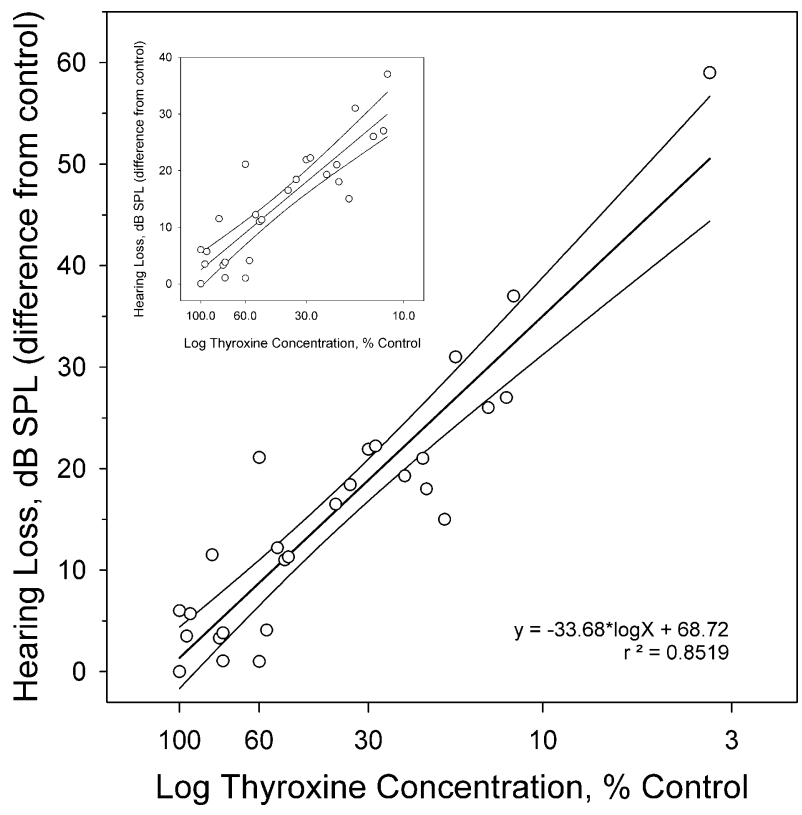

Fig. 1. The correlation between log thyroxine concentration during the early postnatal period and low-frequency hearing loss in adult rats. Thyroxine concentrations are total serum thyroxine on either PND14 or PND21, expressed as percent of control. Hearing loss is the difference score (exposed minus control mean) for $1 \mathrm{kHz}$ thresholds determined in adult rats. The solid line represents the correlation, while the thinner lines represent the $95 \%$ confidence intervals. Insert: The correlation and $95 \%$ confidence intervals without the one extreme upper right value (see text for details).

tion, the analyses were run with and without this data point.

\section{RESULTS AND DISCUSSION}

There was a significant correlation $(p<0.05)$ between T4 concentrations and hearing loss (Fig. 1). The data were highly correlated $\left(r^{2}=0.85\right)$ and fit the following function: dB-loss $=((-33.68 \times \log \mathrm{T} 4)+$ 68.72). The data set without the one extreme value (PTU) was also well correlated $\left(r^{2}=0.78\right)$ and significantly $(p<0.05)$ fit by the following function: $\mathrm{dB}-$ loss $=((-29.87 \times \log \mathrm{T} 4)+62.21)($ see Fig. 1$)$. These data support the conclusion that the degree of hearing loss in adult rats is closely correlated with the decrease in $\mathrm{T} 4$ concentrations during the early postnatal period. This is consistent with the postnatal maturation of the cochlea in the rat (Rubel, 1978), as well as the known sensitive period of the rat cochlea to disruption of THs (Deol, 1976; Puel \& Uziel, 1987; Uziel, 1986) and PHAHs (Crofton et al., 2000a). 
The correlation between $\mathrm{T} 4$ and hearing loss has important implications for assessing the risks of thyroid-related developmental neurotoxicity. This correlation clearly demonstrates that postnatal T4 concentration is a good predictive biomarker of hearing loss in adult rats. In humans, hearing loss is a hallmark symptom of developmental hypothyroidism (e.g., severe iodine deficiency or congenital hypothyroidism) (Goslings et al., 1975; Meyerhoff, 1976; Boyages, 2000). Loss of hearing in humans is a wellrecognized disability that can impair normal psychological development and lead to a decrease in the quality of life (Sataloff \& Sataloff, 1993). The use of T4 as a biomarker for hearing loss in rodents has the advantage of being a well-validated clinical chemistry assay that is easier and cheaper to use when compared to the measurement of auditory thresholds. More work is needed to characterize the dose response of other endpoints of neural development in rodent models with thyroid hormone concentrations during development. Essential to characterizing these correlations is the measurement of hormones during the critical period of development for the target tissue (Howdeshell, 2002). Adverse neurodevelopmental effects are potentially due to a thyroxicant's effects on hormone homeostasis in the dam as well as the fetus or neonate (Boyages \& Halpern, 1993; Delange, 2000; Morreale de Escobar, 2001; Howdeshell, 2002). Thyroid hormones in the fetus or neonate can be affected by (1) a decrease in $\mathrm{TH}$ available from the dam during fetal development (e.g., maternal hypothyroxinemia), (2) placental transfer of the TDC (e.g., perchlorate), (3) lactation transfer of the TDC to the neonate (e.g., PHAHs, perchlorate), and (4) direct exposure to the young rat from drinking water or food. Thus, a key consideration for characterizing the dose-response relationship of any TDC is an understanding of its dosimetry in the fetus and neonate. The current correlation is based mainly on studies of highly lipophilic PHAHs. A consequence of high lipophilicity and long half-life is greater postnatal exposure to these chemicals via lactation compared to fetal exposure (Takagi et al., 1986; Vodicnik \& Lech, 1980; Masuda et al., 1978; Crofton et al., 2000a; Clewell \& Gearhart, 2002). This leads to potentially greater impact on circulating T4 levels during the early postnatal period (Crofton et al., 2000a) compared to water soluble compounds. An exception to this may be if there is active transport of water-soluble compounds to milk such as with perchlorate (Clewell \& Gearhart, 2002; Clewell et al., 2003a, 2003b). This active transport leads to greater postnatal exposure and potentially a larger impact on postnatal hormones. For lipid-soluble chemicals, these characteristics result in a temporal concurrence between peak effects on $\mathrm{T} 4$ and the critical window for low-frequency hearing development in rats (Deol, 1976; Puel \& Uziel, 1987; Uziel, 1986). Chemicals that impact mainly prenatal THs would not therefore be expected to correlate well with hearing loss in rats. This has been shown in a limited fashion in a cross-fostering study with A1254 (Crofton et al., 2000a), where prenatal-only exposure decreased fetal but not postnatal T4 concentrations and had no impact on hearing. Other endpoints (e.g., cognitive function) may be more sensitive to circulating hormone levels compared to hearing loss and may be more appropriate models for extrapolation to humans where cognitive impairment occurs as a consequence of lowlevel disruption in maternal T4 during the fetal period (Man, 1972; Man et al., 1991; Haddow et al., 1999; Pop et al., 1999; Morreale de Escobar et al., 2000).

Derivation of health risk estimates requires a number of important decisions regarding the usefulness of toxicological and health effects data to define a dose-response relationship in humans. Typically, a critical effect is identified from the data array of available toxicological and clinical studies. The point of departure used as the basis of the derivation for the risk estimate is usually the no-observed-adverseeffect level (NOAEL) or another health risk benchmark level such as the benchmark dose (Barnes et al., 1995). Recent emphasis has been placed on using mechanistic insights to inform the integration of diverse data due to study design differences and different endpoint or outcome measures (U.S. EPA, 1999). This includes extending the range of observations for adverse effects with an understanding of the mode of action, and use of biomarker data to inform the dose-response relationship. Acceptance of biomarker data in this context will be best established by mapping the quantitative relationships of the biomarker to those of traditional outcome measures, or at a minimum, by demonstrating its prognostic significance by means of strong predictive correlation (U.S. EPA, 1994). The present work allows determination of these relationships. A 15-dB shift in an auditory threshold was nbsp;chosen as a change at one frequency that could be reliably detected in rats, and would be generally accepted as being clinically significant in humans (cf., Sataloff \& Sataloff, 1993; Crofton \& Zhao, 1997). The present rodent data demonstrate that a 15-dB hearing loss is associated with a T4 concentration of $\log 1.5934$ or a $60 \%$ decrease in T4. This contrasts with recent epidemiological studies showing 
decrements in neurological development in children of mothers with 25\% decreases in T4 (Man, 1972; Man et al., 1991; Haddow et al., 1999; Pop et al., 1999; Morreale de Escobar et al., 2000). Comparison of these epidemiological data to the present work implies that rodents may be less sensitive to hypothyroxinemia compared to humans. The assumptions are that fetal levels are most important for human cochlear development, which occurs primarily in utero (Sulik, 1995), and that human maternal T4 levels will be predictive of fetal levels. In rats, postnatal pup T4 levels are most important for cochlear development, which occurs primarily postnatally (Rubel, 1978). Therefore, early postnatal T4 levels in rats may be a predictive biomarker of the effects of prenatal thyroid disruption in humans. However, since there is no effects data for similar endpoints (e.g., hearing or cognition) in rats and humans, definitive conclusions on this issue are premature at this time.

In summary, the present findings demonstrate a strong correlation between early postnatal total serum T4 concentration with auditory thresholds in rats. This correlation establishes the prognostic power of early postnatal $\mathrm{T} 4$ for adverse neurological consequence of developmental exposure to TDCs in rats. Areas for further refinement include quantitative adjustment of the results for fetal and neonatal dosimetry of specific TDCs. Others are encouraged to characterize the sensitivity of additional neurodevelopmental measures of thyroid hormone disruption.

\section{ACKNOWLEDGMENTS}

The author thanks Drs. Annie Jarabek, Mary E. Gilbert, and R. Thomas Zoeller for comments on an earlier version of this manuscript.

The information in this document has been funded wholly (or in part) by the U.S. Environmental Protection Agency. It has been subjected to review by the National Health and Environmental Effects Research Laboratory and approved for publication. Approval does not signify that the contents reflect the views of the Agency, nor does mention of trade names or commercial products constitute endorsement or recommendation for use.

\section{REFERENCES}

Barnes, D. G., Daston, G. P., Evans, J. S., Jarabek, A. M., Kavlock, R. J., Kimmel, C. A., Park, C., \& Spitzer, H. L. (1995). Benchmark dose workshop: Criteria for use of a benchmark dose to estimate a reference dose. Regulatory Toxicology and Pharmacology, 21, 296-306.
Boyages, S. C. (2000). The neuromuscular system and brain in hypothyroidism. In L. E. Braverman \& R. D. Utiger (Eds.), Werner and Ingbar's the Thyroid: A Fundamental and Clinical Text, 8th ed. (pp. 803-810). Philadelphia: Lippincott Williams and Wilkins.

Boyages, S. C., \& Halpern, J. P. (1993). Endemic cretinism: Toward a unifying hypothesis. Thyroid, 3, 59-69.

Brouwer, A., Morse, D. C., Lans, M. C., Schuur, A. G., Murk, A. J., Klasson-Wehler, E., Bergman, A., \& Visser, T. J. (1998). Interactions of persistent environmental organohalogens with the thyroid hormone system: Mechanisms and possible consequences for animal and human health. Toxicology and Industrial Health, 14, 59-84.

Brucker-Davis, F. (1998). Effects of environmental synthetic chemicals on thyroid function. Thyroid, 8, 827-856.

Capen, C. C. (1994). Mechanisms of chemical injury of thyroid gland. Progress in Clinical and Biological Research, 387, 173191.

Capen, C. C. (1997). Mechanistic data and risk assessment of selected toxic end points of the thyroid gland. Toxicologic Pathology, 25, 39-48.

Capen, C. C. (1998). Correlation of mechanistic data and histopathology in the evaluation of selected toxic endpoints of the endocrine system. Toxicological Letters, 102, 103, 405409.

Clewell, R. A., \& Gearhart, J. M. (2002). Pharmacokinetics of toxic chemicals in breast milk: Use of PBPK models to predict infant exposure. Environmental Health Perspectives, 110, A333A337.

Clewell, R. A., Merrill, E. A., Yu, K. O., Mahle, D. A., Sterner, T. R., Mattie, D. R., Robinson, P. J., Fisher, J. W., \& Gearhart, J. M. (2003a). Predicting fetal perchlorate dose and inhibition of iodide kinetics during gestation: A physiologically-based pharmacokinetic analysis of perchlorate and iodide kinetics in the rat. Toxicological Sciences, 73, 235-255.

Clewell, R. A., Merrill, E. A., Yu, K. O., Mahle, D. A., Sterner, T. A., Fisher, J. W., \& Gearhart, J. M. (2003b). Predicting neonatal perchlorate dose and inhibition of iodide uptake in the rat during lactation using physiologically-based pharmacokinetic modeling. Toxological Sciences, 74, 416-436.

Colborn, T., vom Saal, F. S., \& Soto, A. M. (1993). Developmental effects of endocrine-disrupting chemicals in wildlife and humans. Environmental Health Perspectives, 101, 378-384.

Crofton, K. M., Dean, K. F., Menache, M. G., \& Janssen, R. (1990). Trimethyltin (TMT) effects on auditory function and cochlear pathology. Toxicology and Applied Pharmacology, 105, 123132.

Crofton, K. M., DeVito, M., Kodavanti, P. R. S., Derr-Yellin, E. C., Bushnell, P. J., Padnos, B., Ostby, J., \& Gray, L. E. (1998). Developmental exposure to Aroclor 1254 using a maternal "steady state" exposure model: Hormonal, hepatic, reproductive and neurotoxic effects. Toxicologist, 42(Suppl. 1), 164.

Crofton, K. M., Ding, D., Padich, R., Taylor, M., \& Henderson, D. (2000a). Hearing loss following developmental exposure to polychlorinated biphenyls: A cochlear site of action. Hearing Research, 144, 196-204.

Crofton, K. M., Kodavanti, P. R., Derr-Yellin, E. C., Casey, A. C., \& Kehn, L. S. (2000b). PCBs, thyroid hormones, and ototoxicity in rats: Cross-fostering experiments demonstrate the impact of postnatal lactation exposure. Toxicological Sciences, 57, 131140.

Crofton, K. M., \& Rice, D. C. (1999). Low-frequency hearing loss following perinatal exposure to $3,3^{\prime}, 4,4^{\prime}, 5$ pentachlorobiphenyl (PCB 126) in rats. Neurotoxicology and Teratology, 21, 299-301.

Crofton, K. M., \& Zhao, X. (1997). The ototoxicity of trichloroethylene: Extrapolation and relevance of high-concentration, short-duration animal exposure data. Fundamental Applied Toxicology, 38, 101-106. 
Delange, F. M. (2000). Endemic cretinism. In L. E. Braverman \& R. D. Utiger (Eds.), Werner and Ingbar's the Thyroid: A Fundamental and Clinical Text, 8th ed. (pp. 743-754). Philadelphia: Lippincott Williams and Wilkins.

Deol, M. S. (1976). The role of thyroxine in the differentiation of the organ of Corti. Acta Otolaryngologica, 81, 429-435.

DeVito, M., Biegel, L., Brouwer, A., Brown, S., Brucker-Davis, F., Cheek, A. O., Christensen, R., Colborn, T., Cooke, P., Crissman, J., Crofton, K., Doerge, D., Gray, E., Hauser, P., Hurley, P., Kohn, M., Lazar, J., McMaster, S., McClain, M., McConnell, E., Meier, C., Miller, R., Tietge, J., \& Tyl, R. (1999). Screening methods for thyroid hormone disruptors. Environmental Health Perspectives, 107, 407-415.

Escobar-Morreale, H. F., Obregon, M. J., Hernandez, A., Escobar del Rey, F., \& Morreale de Escobar, G. (1997). Regulation of iodothyronine deiodinase activity as studied in thyroidectomized rats infused with thyroxine or triiodothyronine. Endocrinology, 138, 2559-2568.

Fiolet, D. C. M., Cuijpers, C. E. J., \& Lebret, E. (1997). Exposure to organic compounds and thyroid hormone plasma levels in human newborns. Organohalogen Compounds, 34, 459465.

Goldey, E. S., \& Crofton, K. M. (1998). Thyroxine replacement attenuates hypothyroxinemia, hearing loss, and motor deficits following developmental exposure to Aroclor 1254 in rats. Toxicological Sciences, 45, 94-105.

Goldey, E. S., Kehn, L. S., Lau, C., Rhenberg, G. L., \& Crofton, K. M. (1995a). Developmental exposure to polychlorinated biphenyls (Aroclor 1254) reduces circulating thyroid hormone concentrations and causes hearing deficits in rats. Toxicology and Applied Pharmacology, 135, 77-88.

Goldey, E. S., Kehn, L. S., Rhenberg, G. L., \& Crofton, K. M. (1995b). Effects of developmental hypothyroidism on auditory and motor function in the rat. Toxicology and Applied Pharmacology, 135, 67-76.

Goldey, E. S., Lau, C., Kehn, L. S., \& Crofton, K. M. (1996). Developmental dioxin exposure: Disruption of thyroid hormones and ototoxicity. Toxicologist, 30, 225.

Goslings, B. M., Djokomoeljanto, R., Hoedijono, R., Soepardjo, H., \& Querido, A. (1975). Studies on hearing loss in a community with endemic cretinism in central Java, Indonesia. Acta Endocrinologica, 78, 705-713.

Haddow, J. E., Palomaki, G. E., Allan, W. C., Williams, J. R., Knight, G. J., Gagnon, J., O'Heir, C. E., Mitchell, M. L., Hermos, R. J., Waisbren, S. E., Faix, J. D., \& Klein, R. Z. (1999). Maternal thyroid deficiency during pregnancy and subsequent neuropsychological development of the child. New England Journal of Medicine, 341, 549-555.

Hendrich, C. E., \& Porterfield, S. P. (1996). Ribosomal protein synthesis in 16 and 19 day gestation fetuses of hypothyroid mothers. Proceedings of the Society for Experimental Biology and Medicine, 213, 273-280.

Herr, D. W., Goldey, E. S., \& Crofton, K. M. (1996). Developmental exposure to Arochlor 1254 produces low frequency alterations in adult rat brainstem auditory evoked responses (BAERs). Fundamental Applied Toxicology, 33, 120-128.

Hill, R. N., Crisp, T. M., Hurley, P. M., Rosenthal, S. L., \& Singh, D. V. (1998). Risk assessment of thyroid follicular cell tumors. Environmental Health Perspectives, 106, 447-457.

Hood, A., \& Klaassen, C. D. (2000). Differential effects of microsomal enzyme inducers on in vitro thyroxine $(\mathrm{T}(4))$ and triiodothyronine (T(3)) glucuronidation. Toxicological Sciences, $55,78-84$.

Howdeshell, K. L. (2002). A model of the development of the brain as a construct of the thyroid system. Environmental Health Perspectives, 110(Suppl 3), 337-348.

Hurley, P. M. (1998). Mode of carcinogenic action of pesticides inducing thyroid follicular cell tumors in rodents. Environmental Health Perspectives, 106, 437-445.
Klaassen, C. D., \& Hood, A. M. (2001). Effects of microsomal enzyme inducers on thyroid follicular cell proliferation and thyroid hormone metabolism. Toxicologic Pathology, 29, 34-40.

Koopman-Esseboom, C., Morse, D. C., Weisglas-Kuperus, N., Lutke-Schipholt, I., VanderPaauw, C. G., Tuinstra, L. G. M. T., Brower, A., \& Sauer, P. J. J. (1994). Effects of dioxins and polychlorinated biphenyls on thyroid hormone status of pregnant women and their infants. Pediatric Research, 36, 468-473.

Ladenson, P. W. (2000). Diagnosis of hypothyroidism. In L. E. Bravermen \& R. D. Utiger (Eds.), Werner and Ingbar's the Thyroid: A Fundamental and Clinical Text, 8th ed. (pp. 848852). Philadelphia: Lippincott Williams and Wilkins.

Langer, P., Tajtakova, M., Fodor, G., Kocan, A., Bohov, P., Michalek, J., \& Kreze, A. (1998). Increased thyroid volume and prevalence of thyroid disorders in an area heavily polluted by polychlorinated biphenyls. European Journal of Endocrinology, 139, 402-409.

Lavado-Autric, R., Auso, E., Garcia-Velasco, J. V., Arufe Mdel, C., Escobar del Rey, F., Berbel, P., \& Morreale de Escobar, G. (2003). Early maternal hypothyroxinemia alters histogenesis and cerebral cortex cytoarchitecture of the progeny. Journal of Clinical Investigation, 111, 1073-1082.

Longnecker, M. P., Gladen, B. C., Patterson, D. G. Jr., \& Rogan, W. J. (2000). Polychlorinated biphenyl (PCB) exposure in relation to thyroid hormone levels in neonates. Epidemiology, 112, 4954 .

Man, E. B. (1972). Thyroid function in pregnancy and infancy. Maternal hypothyroxinemia and retardation of progeny. $C R C$ Critical Reviews in Clinical Laboratory Science, 3, 203-225.

Man, E. B., Brown, J. F., \& Serunian, S. A. (1991). Maternal hypothyroxinemia: Psychoneurological deficits of progeny. Annals of Clinical and Laboratory Science, 21, 227-239.

Masuda, Y., Kagawa, R., Tokudome, S., \& Kuratsune, M. (1978). Transfer of polychlorinated biphenyls to the foetuses and offspring of mice. Food and Cosmetics Toxicology, 16, 33-37.

McClain, R. M. (1995). Mechanistic considerations for the relevance of animal data on thyroid neoplasia to human risk assessment. Mutation Research, 333, 131-142.

McClain, R. M., Levin, A. A., Posch, R., \& Downing, J. C. (1989). The effect of phenobarbital on the metabolism and excretion of thyroxine in rats. Toxicology and Applied Pharmacology, 99, 216-228.

Meyerhoff, E. L. (1976). The thyroid and audition. Laryngoscope, $86,483-489$.

Morreale de Escobar, G. (2001). The role of thyroid hormone in fetal neurodevelopment. Journal of Pediatric Endocrinology Metabolism, 14(Suppl 6), 1453-1462.

Morreale de Escobar, G., Calvo, R., Escobar del Rey, F., \& Obregon, M. J. (1993). Differential effects of thyroid hormones on growth and Thyrotropic hormones in rat fetuses near term. Endocrinology, 132, 2056-2064.

Morreale de Escobar, G., Obregon, M. J., \& Escobar del Rey, F. (2000). Is neuropsychological development related to maternal hypothyroidism or to maternal hypothyroxinemia? Journal of Clinical Endocrinology and Metabolism, 85, 3975-3987.

Müller, M. (1991). Developmental changes of frequency representation in the rat cochlea. Hearing Research, 56, 1-7.

Nagayama, J., Okamura, K., Iida, T., Hirakawa, H., Matsueda, T., Tsuji, H., Hasegawa, M., Sato, K., Ma, H.-Y., Yanagawa, T., Igarashi, H., Fukushige, J., \& Watanabe, T. (1998). Postnatal exposure to chlorinated dioxins and related chemicals on thyroid hormone status in Japanese breast-fed infants. Chemosphere, 37, 1789-1793.

Oppenheimer, J. H., Bernstein, G., \& Surks, M. I. (1968). Increased thyroxine turnover and thyroidal function after stimulation of hepatocellular binding of thyroxine by phenobarbital. Journal of Clinical Investigation, 47, 1399-1406.

Pop, V. J., Kuijpens, J. L., van Baar, A. L., Verkerk, G., van Son, M. M., de Vijlder, J. J., Vulsma, T., Wiersinga, W. M., Drexhage, 
H. A., \& Vader, H. L. (1999). Low maternal free thyroxine concentrations during early pregnancy are associated with impaired psychomotor development in infancy. Clinical Endocrinology, 50, 149-155.

Porterfield, S. P. (2000). Thyroidal dysfunction and environmental chemicals-Potential impact on brain development. Environmental Health Perspectives, 108(Suppl 3), 433-438.

Puel, J.-L., \& Uziel, A. (1987). Correlative development of cochlear action potential sensitivity, latency, and frequency selectivity. Development in Brain Research, 37, 179-188.

Rubel, E. W. (1978). Ontogeny of structure and function in the vertebrate auditory system. In M. Jacobson (Ed.), Handbook of Sensory Physiology, vol. 9 (pp. 135-237). Berlin: SpringerVerlag.

Rubel, E. W. (1984). Ontogeny of auditory system function. Annual Review of Physiology, 46, 213-229.

Sataloff, R. T., \& Sataloff, J. (1993). Hearing Loss, 3rd ed. New York: Marcel Dekker, Inc.

Sprenkle, P. M., McGee, J., Bertoni, J. M., \& Walsh, E. J. (2001). Prevention of auditory dysfunction in hypothyroid Tshr mutant mice by thyroxin treatment during development. Journal of Association for Research in Otolaryngology, 2, 348-361.

Sulik, K. K. (1995). Embryology of the ear. In R. J. Gorlin, H. V. Toriello, \& M. M. Cohen (Eds.), Hereditary Hearing Loss and Its Syndromes (pp. 23-42). New York: Oxford University Press.

Takagi, Y., Aburada, S., Hashimoto, K., \& Kitaura, T. (1986). Transfer and distribution of accumulated (14C) polychlorinated biphenyls from maternal to fetal and suckling rats. Archives of Environmental Contamination and Toxicology, 15, 709-715.

Taylor, M. M., Hedge, J. M., Gilbert, M. E., DeVito, M. J., \& Crofton, K. M. (2003). Perinatal exposure to a polybrominated diphenyl ether mixture (DE-71): Disruption of thyroid homeostasis and neurobehavioral development. Toxicologist, 72(Suppl 1), 124.

Timiras, P. S., \& Nzekwe, E. U. (1989). Thyroid hormones and nervous system development. Biology of the Neonate, 55, 376-385.
U.S. EPA (Environmental Protection Agency). (1994). Methods for Derivation of Inhalation Reference Concentrations and Application of Inhalation Dosimetry. EPA/600/8-90-066F, October. Washington, DC: Office of Health and Environmental Assessment.

U.S. EPA (Environmental Protection Agency). (1999). Proposed guidelines for carcinogen risk assessment (April 23, 1996). Federal Register, 6, 17960-18011.

Uziel, A. (1986). Periods of sensitivity to thyroid hormone during the development of the organ of Corti. Acta Otolaryngolica Supplementum, 429, 23-27.

Uziel, A., Gabrion, J., Ohresser, M., \& Legrand, C. (1981). Effects of hypothyroidism on the structural development of the organ of Corti in the rat. Acta Otolaryngolica, 92, 469-480.

Vodicnik, M. J., \& Lech, J. J. (1980). The transfer of $2,4,5,2^{\prime}, 4^{\prime}, 5^{\prime}-$ hexachlorobiphenyl to fetuses and nursing offspring. I. Disposition in pregnant and lactating mice and accumulation in young. Toxicology and Applied Pharmacology, 54, 293300.

Wolff, J. (1998). Perchlorate and the thyroid gland. Pharmacological Review, 50, 89-105.

Young, J. S., \& Fechter, L. D. (1983). Reflex inhibition procedures for animal audiometry: A technique for assessing ototoxicity. Journal of the Acoustical Society of America, 73, 16861693.

Zhou, T., Taylor, M. M., DeVito, M. J., \& Crofton, K. M. (2002). Developmental exposure to brominated diphenyl ethers results in thyroid hormone disruption. Toxicological Sciences, 66, $105-116$.

Zoeller, R. T., \& Crofton, K. M. (2000). Thyroid hormone action in fetal brain development and potential for disruption by environmental chemicals. Neurotoxicology, 21, 935-945.

Zoeller, T. R., Dowling, A. L., Herzig, C. T., Iannacone, E. A., Gauger, K. J., \& Bansal, R. (2002). Thyroid hormone, brain development, and the environment. Environmental Health Perspectives, 110 (Suppl 3), 355-361. 